\title{
As narrativas de termodinâmica nos livros didáticos angolanos e a conceptualização dos seus leitores ${ }^{1}$
}

\author{
Ana Sofia Afonso² \\ orcid.org/0000-0003-2151-5196 \\ Daniel A. Freitas ${ }^{3}$ \\ orcid.org/0000-0003-4793-8533
}

\section{Resumo}

A recente Lei de Bases do Sistema de Educação e Ensino Angolano atribui um papel central ao livro didático na formação de indivíduos. Nesse período de paz recente e de prosperidade em Angola, procura-se uma educação de qualidade que possa acompanhar os desenvolvimentos sociais e econômicos do país. Uma educação que possa contribuir não só para as inovações científicas e tecnológicas na sociedade angolana, mas também para formar indivíduos críticos e atuantes. Angola é um dos maiores exportadores de petróleo mundial, por esse motivo, as questões energéticas constituem um dos assuntos a incluir no ensino das ciências. Dado que esse ensino se encontra dependente dos livros didáticos, este estudo procurou analisar qual a abordagem da termodinâmica nos livros didáticos de física, de modo a inferir em que medida as suas propostas veiculam uma relação entre o conhecimento científico e o posicionamento do indivíduo na sociedade sobre questões energéticas. A análise dos textos de termodinâmica teve em consideração o contexto sócio cultural da sua produção e permitiu constatar que a estrutura discursiva é fechada, com enfoque no conteúdo conceptual, e sem propostas metodológicas promotoras do pensamento divergente. 0 leitor é conceptualizado como alguém pertencente a um grupo de elite, "pré especialista" e com elevado "capital científico" e intrinsecamente motivado.

\section{Palavras-Chave}

Angola - Análise do discurso - Livro didático - Termodinâmica.

\footnotetext{
1- Agradecimentos: 0 contributo de Ana S. Afonso para este trabalho foi financiado pelo CIEd - Centro de Investigação em Educação, Instituto de Educação, Universidade do Minho, projetos UIDB/01661/2020 e UIDP/01661/2020, através de fundos nacionais da FCT/MCTES-PT.

0 contributo de Daniel A. Freitas para este trabalho foi financiado pelo "Instituto Nacional de Gestão de Bolsas de Estudos INAGBE - Angola".

2- Universidade do Minho, Braga, Portugal. Contato: aafonso@ie.uminho.pt

3- Instituto Superior de Ciências de Educação do Huambo, Huambo, Angola. Contato: dafreitas90@gmail.com
} 


\section{Narratives of thermodynamics in Angolan textbooks and the conceptualization of their readers}

\section{Abstract}

The recent Angolan Educational Law assigns textbooks a central role in the learning process. In the current period of peace and prosperity in Angola, the country looks for an education that goes along with the country's social and economic developments. An education that contributes to scientific and technological innovations in Angolan society, and prepares critical and active citizens. Angola is one of the largest exporters of crude oil in the world, and hence, energy is an important subject to be included in science teaching. Since, in Angola, science teaching is mainly based on textbooks, this study aimed at analysing the thermodynamics approaches provided in physics textbooks. From this analysis, we also aim to infer to what extent textbooks' proposals convey a relationship between scientific knowledge and an individual's standpoint in society on energy. The review of the thermodynamics texts, which took into account the socio-cultural context of their production, revealed that they hold a closed discursive structure, with a focus on conceptual content; and that there is an absence of methodological proposals for promoting divergent thinking. Furthermore, the reader is conceptualized as someone belonging to an elite group, "pre-specialist", with high "scientific capital", and intrinsically motivated.

\section{Keywords}

Angola - Discourse analysis - Textbook - Thermodynamics.

\section{Contexto e objetivos}

Após quase 30 anos de Guerra Civil em Angola - a qual gerou uma crise humanitária e danificou severamente as infraestruturas do país - a paz restabeleceu-se em 2002. Se inicialmente a reconstrução das infraestruturas físicas do país constituíram uma prioridade, atualmente procura-se também a reconstrução do capital humano em áreas como as ciências e a tecnologia para impulsionar o desenvolvimento econômico e social (ANGOLA, 2018). Deste modo, compreende-se que a educação, designadamente em ciências, dos jovens angolanos, seja também uma prioridade nacional segundo a Lei de Bases do Sistema de Educação e Ensino - LBSEE, lei 17/16 de 7 de outubro (ANGOLA, 2016). O Sistema de Educação e Ensino de Angola, tutelado pelo Ministério da Educação, encontra-se dividido em três níveis de ensino: educação pré-escolar; ensino primário (da $1^{\mathrm{a}}$ à $6^{\mathrm{a}}$ classe) e ensino secundário. Este último compreende o $\mathrm{I}^{\mathrm{o}}$ ciclo do ensino secundário (7 à $9^{\text {a }}$ classe) e o II ${ }^{\circ}$ ciclo do ensino secundário ( $10^{\mathrm{a}}$ à $12^{\mathrm{a}}$ classe). A escolaridade é obrigatória do ensino primário até ao final do $\mathrm{I}^{\circ}$ ciclo do ensino secundário e a matriz curricular para essa etapa inclui as disciplinas que constam do Quadro 1. 
Durante a escolaridade obrigatória as ciências são inicialmente abordadas de modo integrado, em estudo do meio e em ciências da natureza, sendo ensinadas como disciplinas independentes (física, química, biologia) da $7^{\text {a }}$ à $9^{\text {a }}$ classe (Quadro 1). É ainda de notar que o I ${ }^{\circ}$ ciclo do ensino secundário inclui também a disciplina de educação laboral, a qual procura criar um vínculo entre a educação e o mercado de trabalho (INIDE/MED, 2019). Contudo, a finalidade da educação, e em particular da educação em ciências, durante a escolaridade obrigatória vai além da potencial inserção dos alunos no mercado de trabalho. Procura também formar cidadãos atuantes na sociedade em que vivem (ANGOLA, 2016):

i) "Aprofundar os fundamentos de uma cultura humanística, baseada nos valores morais, éticos, cívicos e patrióticos";

ii)“Criar hábitos de trabalho individual e em grupo e favorecer o desenvolvimento de atitudes de reflexão metódica e de adaptação à mudança.” (ANGOLA, 2016, p. 3997).

Após a conclusão da escolaridade obrigatória, os alunos podem ingressar no II $^{\circ}$ ciclo do ensino secundário. Nesse ciclo, os alunos podem optar por continuar a sua formação, ingressando no II $^{\circ}$ ciclo do ensino secundário geral, ou podem optar por uma via profissionalizante (por exemplo, pela formação de professores para o ensino primário ou por uma formação de técnicos para os diferentes ramos de atividade). No II $^{\circ}$ ciclo do ensino secundário geral, enfoque deste trabalho, as ciências (física, química, biologia e geologia) são ensinadas como disciplinas independentes as quais, em conjunção com as restantes disciplinas da matriz curricular para esse ciclo (tais como, língua portuguesa, língua estrangeira, matemática, informática, educação física e filosofia) devem contribuir para que os jovens sejam preparados para o prosseguir estudos no ensino superior ou para a entrada no mundo do trabalho. Mas não só, devem também:

Desenvolver uma visão do mundo assente no pensamento filosófico, lógico e abstrato e a capacidade de avaliar a aplicação de modelos científıcos na resolução de problemas da vida prática [e] consolidar os valores patrióticos, morais e cívicos, desenvolvendo o espírito de

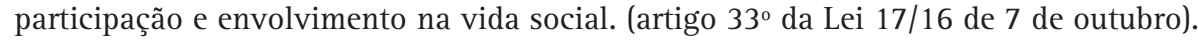

Essa preocupação com a educação em ciências para todos ao longo de toda a escolaridade, embora recente em Angola (Lei 17/16 de 7 de outubro), é consensual entre os investigadores e defendida pelas autoridades educacionais de vários países (por exemplo, NRC, 2012; EUROPEAN COMISSION, 2015). Defende-se que os alunos e os cidadãos necessitam saber ciências, saber acerca das ciências e saber sobre ciências (HODSON, 2010), por razões sociais, econômicas, utilitárias, democráticas e culturais (GREGORY; MILLER, 1998). Em Angola, tal como noutros países africanos, com um passado de colonização e de dependência econômica no quadro mundial, existem profundas desigualdades culturais e sociais em diferentes cidades, em áreas rurais e urbanas, por isso é que é importante discutir que os cidadãos necessitam das ciências. Para muitos jovens o ensino das ciências poderá apenas contribuir para a sua emancipação com vista à sobrevivência e à melhoria da qualidade das suas vidas (JEGEDE, 1997), não desvalorizando as suas identidades 
Quadro 1- Disciplinas que constam da matriz curricular durante a escolaridade obrigatória

\begin{tabular}{|c|c|c|c|c|c|c|c|c|c|}
\hline \multirow[t]{2}{*}{ Disciplinas na escolaridade obrigatória } & \multicolumn{6}{|c|}{$\begin{array}{l}\text { Ensino primário } \\
\text { (Classes) }\end{array}$} & \multicolumn{3}{|c|}{$\begin{array}{l}\text { I Ciclo do Ensino secundário } \\
\text { (Classes) }\end{array}$} \\
\hline & $1 .^{a}$ & $2 .^{a}$ & $3 .^{a}$ & $4 .^{a}$ & $5 .^{a}$ & $6 .^{a}$ & $7 .^{a}$ & $8 .^{a}$ & 9. ${ }^{a}$ \\
\hline Língua Portuguesa & $\sqrt{ }$ & $\sqrt{ }$ & $\sqrt{ }$ & $\sqrt{ }$ & $\sqrt{ }$ & $\sqrt{ }$ & $\sqrt{ }$ & $\sqrt{ }$ & $\sqrt{ }$ \\
\hline Língua Estrangeira & & & & & & & $\sqrt{ }$ & $\sqrt{ }$ & $\sqrt{ }$ \\
\hline Matemática & $\sqrt{ }$ & $\sqrt{ }$ & $\sqrt{ }$ & $\sqrt{ }$ & $\sqrt{ }$ & $\sqrt{ }$ & $\sqrt{ }$ & $\sqrt{ }$ & $\sqrt{ }$ \\
\hline Estudo do Meio & $\sqrt{ }$ & $\sqrt{ }$ & $\sqrt{ }$ & $\sqrt{ }$ & & & & & \\
\hline Ciências da Natureza & & & & & $\sqrt{ }$ & $\sqrt{ }$ & & & \\
\hline Biologia & & & & & & & $\sqrt{ }$ & $\sqrt{ }$ & $\sqrt{ }$ \\
\hline Física & & & & & & & $\sqrt{ }$ & $\sqrt{ }$ & $\sqrt{ }$ \\
\hline Química & & & & & & & $\sqrt{ }$ & $\sqrt{ }$ & $\sqrt{ }$ \\
\hline História & & & & & $\sqrt{ }$ & $\sqrt{ }$ & $\sqrt{ }$ & $\sqrt{ }$ & $\sqrt{ }$ \\
\hline Geografia & & & & & $\sqrt{ }$ & $\sqrt{ }$ & $\sqrt{ }$ & $\sqrt{ }$ & $\sqrt{ }$ \\
\hline Ed. Moral e Cívica & & & & & $\sqrt{ }$ & $\sqrt{ }$ & $\sqrt{ }$ & $\sqrt{ }$ & $\sqrt{ }$ \\
\hline Ed. Manual e Plástica & $\sqrt{ }$ & $\sqrt{ }$ & $\sqrt{ }$ & $\sqrt{ }$ & $\sqrt{ }$ & $\sqrt{ }$ & $\sqrt{ }$ & $\sqrt{ }$ & $\sqrt{ }$ \\
\hline Ed. Musical & $\sqrt{ }$ & $\sqrt{ }$ & $\sqrt{ }$ & $\sqrt{ }$ & $\sqrt{ }$ & $\sqrt{ }$ & & & \\
\hline Educação Física & $\sqrt{ }$ & $\sqrt{ }$ & $\sqrt{ }$ & $\sqrt{ }$ & $\sqrt{ }$ & $\sqrt{ }$ & $\sqrt{ }$ & $\sqrt{ }$ & $\sqrt{ }$ \\
\hline Educação Laboral & & & & & & & $\sqrt{ }$ & $\sqrt{ }$ & $\sqrt{ }$ \\
\hline
\end{tabular}

Fonte: (INIDE/MED, 2019).

culturais, designadamente a cultura africana assente na cooperação (SHUMBA, 2017). Para outros jovens, o ensino das ciências poderá contribuir para desenvolver competências, conhecimentos e atitudes necessárias para prosseguir estudos nessa área do conhecimento e para participar em processos de decisão que envolvam assuntos científicos (RENNIE; STOCKLMAYER; GILBERT, 2019). Os assuntos energéticos constituem um dos assuntos científicos com relevância na sociedade angolana, na medida em que o seu desenvolvimento tem vindo a ser impulsionado pela exploração e exportação do petróleo (RODRIGUES, 2013). Contudo, os compromissos assumidos por Angola no âmbito internacional - a Agenda 2063 da União Africana (UA) e a Agenda 2030 da Organização das Nações Unidas - têm exigido um novo olhar sobre o setor energético, procurando-se:

Otimizar a localização e a disponibilidade da geração térmica existente, bem como aumentar a potência instalada, designadamente em energias novas e renováveis. (ANGOLA, 2018, p. 177).

Esses desafios energéticos são complexos e controversos. Se, por um lado, Angola tem um papel de destaque como produtor de petróleo em África, podendo aumentar a capacidade de refinamento e de expansão das indústrias de derivados de petróleo de modo competitivo no mercado internacional (ANGOLA, 2018), por outro, os compromissos internacionais do governo com a preservação da biodiversidade e com ações no âmbito das alterações climáticas, exigem um uso sustentável dos recursos energéticos não 
renováveis e uma minimização dos impactos causados pela exploração de combustíveis fósseis (ANGOLA, 2018). Até porque, o uso de combustíveis fósseis e o seu impacto no aquecimento global, colocam parte do território angolano em riscos climáticos com implicações negativas na biodiversidade, na agricultura ou nos programas de combate à pobreza (GOMES, 2013).

Aceitando que a escola em Angola se sustenta nos princípios de educação liberal para o século XXI (Lei 17/16 de 7 de outubro), essa não pode alhear-se de preparar os jovens para lidar com a complexidade dos desafios energéticos. Tal pressupõe desenvolver um sentido de responsabilidade social, capacidades intelectuais (por exemplo, comunicação, capacidades analíticas e de resolução de problemas) transferíveis para contextos do mundo real e uma compreensão aprofundada de áreas científicas centrais (AAC \& U, 2011), de que é exemplo a termodinâmica. A termodinâmica faz parte dos programas de física da $10^{\mathrm{a}}$ classe do II $^{\circ}$ ciclo do ensino secundário geral, sendo-lhe dedicada uma carga letiva de 36 horas. Essa temática insere-se num currículo de ciências que, de acordo com a tipologia de Roberts (2011), se aproxima de uma visão interior da ciência: um olhar disciplinar para os produtos e processos da própria ciência (Visão I). Essa visão contrasta com aquela que hoje se defende para a formação dos cidadãos e na qual os contextos do dia a dia funcionam como organizadores para o ensino de temas científicos (ROBERTS, 2011) (Visão II). A consistência dos programas de física do II $^{\circ}$ ciclo do ensino secundário geral com a Visão I pode ser, em parte, explicada com o fato de esses serem anteriores à LBSEE em vigor, os quais tinham como meta a formação superior e/ou formação profissional dos alunos (INIDE, 2014). Essa dissonância entre os princípios da LBSEE e os programas de física não significa necessariamente que não ocorra uma integração de contextos ou situações do dia a dia para tratar temas socialmente relevantes em disciplinas organizadas de modo tradicional (MEMBIELA; PADILLA, 2005).

Contudo, essa integração constitui um desafıo para os professores em países como Angola; se por um lado, os jovens desses países apresentam, em comparação com os alunos dos países ocidentais, atitudes mais positivas em relação às ciências e um desejo maior de emprego em áreas relacionadas com as ciências (SJOBERG; SCHREINER, 2005), por outro, muitos professores não possuem as habilitações adequadas para ensinar física (RODRIGUES, 2013), pois muitos não se sentem confortáveis para ensinar para além do status quo. Independentemente da existência de um bom ou mau currículo, cabe ao professor enriquecer a aprendizagem dos alunos com auxílio de recursos que permitam uma aprendizagem contextualizada (GILBERT, 2006). Em Angola poucos são os recursos disponíveis para enriquecer a aprendizagem dos alunos, por exemplo, ao contrário do que acontece na América Latina, poucos são os museus de ciência existentes (WALKER et al., 2020). Como resultado, o livro didático é o recurso mais utilizado para estruturar a atividade docente em Angola (BUZA, 2007). A importância desse recurso pedagógico é reconhecida na LBSEE (Lei 17/16, de 7 de outubro), que determina que a sua utilização é de carater obrigatório nos ensinos primário e secundário. Ao contrário de outros países, nomeadamente Portugal, a Lei de Bases do Sistema de Educação e Ensino Angolano (Lei 17/16 de 7 de outubro) não estabelece um intervalo temporal para que os livros didáticos estejam em vigor, nem existe ainda uma legislação própria para a sua edição. 
Pelo exposto, procurou-se analisar qual a abordagem da termodinâmica nos manuais escolares de física angolanos, de modo a inferir em que medida as suas propostas veiculam uma relação entre o conhecimento científico e o posicionamento do indivíduo na sociedade sobre questões energéticas. Esse olhar sobre o livro didático será efetuado a partir da análise do seu texto e tendo em consideração o contexto socio cultural em que decorre (MARTINS, 2012). Assim, este estudo, focado em capítulos de termodinâmica, procura responder às questões de investigação as quais serão articuladas adiante, na seção “discussão":

- Que narrativas estão presentes nos textos dos capítulos de termodinâmica de livros didáticos angolanos?

- Que linhas discursivas marcam o desenrolar dessas narrativas?

- Como é que os autores conceptualizam o leitor destes capítulos de termodinâmica?

\section{O discurso do livro didático de ciência}

0 livro didático de ciências pode ser entendido como: um "livro intencionalmente concebido para servir de suporte escrito ao ensino de uma disciplina [por exemplo, de ciências] no seio de uma instituição escolar" (SANTOS, 2001, p. 23). Esse recurso didático apresenta algumas características que o distinguem de outros livros que comunicam ciências, designadamente: a estabilidade lexical e gramatical, o uso de estruturas de didatização de conteúdos (por exemplo, definições, exercícios, experiências, leituras complementares), a existência de formatos de apresentação e a organização de atividades de sala de aula (MARTINS, 2012). Essas características dos livros didáticos têm subjacente perspetivas de ensino e de aprendizagem das ciências que se encontram enraizadas na prática social de ensinar ciências na escola (MARTINS, 2007) e que se encontram, muitas vezes, em tensão com as políticas educativas de um dado país.

Entender o livro didático requer compreender o contexto sócio cultural específico em que este se insere, que, de fato, não pode ser compreendido como uma simples desconstrução do conteúdo científico numa versão acessível ao aluno. $\mathrm{Na}$ sua análise não se pode deprezar as ideologias e valores em que se encontra embebido e que se relacionam, entre outros aspetos, com políticas pedagógicas ou com a produção do livro didático (por exemplo, lugares sociais que os autores assumem no texto ou expectativas sobre os leitores) (MARTINS, 2012; NASCIMENTO; MARTINS, 2005). Nesse contexto, o livro didático pode ser visto como um objeto cultural, materializado a partir do seu texto que representa o discurso escolar e que integra vários discursos, como o científico, o pedagógico, ou o político (MOREIRA; MARTINS, 2015). Tais discursos interagem originando pontos de tensão, conflito ou cooperação que estão presentes no texto do livro didático (MARTINS, 2012).

A análise linguística do texto do livro didático, no contexto sociocultural específico em que decorre o ato de comunicação (KÖVECSES, 2010), abre novas agendas de pesquisa (MARTINS, 2012). Uma dessas linhas foca-se no relacionamento entre as ciências, a tecnologia e a sociedade, em particular no papel do aluno enquanto cidadão. Nessa linha de pesquisa, mais do que analisar o tipo de interrelações entre as ciências, a tecnologia e a 
sociedade presentes no livro didático, bem como a natureza das tarefas de aprendizagem como tem vindo a ser relatado em vários estudos de investigação (por exemplo, AMARAL; XAVIER; MACIEL, 2009, PEIXE et al., 2017) - é necessário estender a análise a um nível micro, buscando as interrelações, expressas e não expressas, no texto em articulação com o contexto específico em que se insere o livro didático, os sujeitos a quem se destina e os discursos que o compõem (MARTINS, 2012). Assim, ao compreender a estrutura discursiva do texto é possível averiguar como o texto abre (ou não) espaço para a mudança em direção a uma visão de transformação da educação. Estudos com essa análise textual têm vindo a ser realizados no Brasil. Um deles, no âmbito da mecânica e educação para o trânsito, revela que o discurso do livro didático incita ao empoderamento do aluno, sendo empregue um discurso híbrido no qual o discurso do dia a dia (por exemplo, dirigir) é incorporado no conteúdo científico tradicional (MOREIRA; PEREIRA; MARTINS, 2017). Num outro estudo (NASCIMENTO; MARTINS, 2005), constata-se que, embora incitando o aluno a posicionar-se sobre assuntos de genética, os livros didáticos veem o leitor como alguém que necessita aprender conteúdos básicos de genética de modo a aplicá-los a situações do cotidiano. 0 discurso científico sobre genética é valorizado, sendo esperado do leitor competências para o compreender. 0 significado destes resultados torna-se especialmente interessante quando articulado com as particularidades de um ensino das ciências com orientações na linha das Ciências-Tecnologia-Sociedade (CTS) no Brasil, as quais - ao basearem-se nos pressupostos da educação emancipatória de Paulo Freire procuram a emancipação social dos sujeitos e a sua transformação com vista à melhoria da qualidade das suas vidas (BUENO DE ABREU; FERNANDES; MARTINS, 2008).

\section{Metodologia}

Em Angola foram encontrados dois livros didáticos para a $10^{\text {a }}$ classe do ensino secundário, ambos editados pela editora Plural, autenticados pelo Instituto Nacional de Investigação e Desenvolvimento da Educação (INIDE), escritos por autores portugueses e adotados nas escolas públicas e privadas de Angola, durante o período compreendido entre os anos letivos de 2015 a 2020. A extensão do capítulo "termodinâmica" em cada um dos livros didáticos é diferente, sendo maior no livro M2, editado em 2016, do que no livro M1 editado em 2015 (Quadro 2). 0 corpus de análise é composto pelos textos dos capítulos de termodinâmica dos livros didáticos de Física para a $10^{\mathrm{a}}$ classe do ensino secundário geral.

Quadro 2 - Características dos capítulos "termodinâmica" dos manuais escolares analisados

\begin{tabular}{rr|c:c}
\hline \multirow{2}{*}{ Livro } & Autores & Ano & n. ${ }^{\circ}$ páginas \\
\hline \multirow{2}{*}{ LD1 } & ARIEIRO Maria E.; LEITÃO, Paula & 2015 & $\vdots$ \\
\hline LD2 & FERNANDES, Sofia; MAGALHÃES, Rui; OLIVEIRA, Ana & 23 \\
\hline
\end{tabular}

Fonte: Dados da pesquisa. 
A investigação dos capítulos partiu de uma análise macro, na qual se identificou a linha discursiva que marca a narrativa presente no texto, utilizando para tal o quadro conceptual de Scott (1988), e no qual se inclui o desenvolvimento de uma linha conceptual e o desenvolvimento de uma linha epistemológica. 0 texto que apresenta uma linha conceptual caracteriza-se por guiar os alunos na construção de uma explicação científica (por exemplo, respondendo a questões chave que podem ser apresentadas de forma implícita ou explícita) e por destacar ideias chave. 0 texto que apresenta uma linha epistemológica caracteriza-se por veicular ideias acerca da natureza do conhecimento científico (SCOTT, 1988). Essa análise macro permitiu constatar que o texto era marcado por narrativas que seguiam linhas conceptuais, nas quais os elementos dessas narrativas foram identificados, usando como referência o trabalho de Ogborn et al. (1996). Estes autores assumem que a estruturação das explicações científicas pode ser vista como a construção de uma narrativa, com um fio condutor, na qual se podem identificar quatro momentos: 1) "criar diferenças" - procura-se evidenciar uma diferença entre as ideias dos autores e as ideias do leitor num dado tema, bem como persuadir o leitor para algo que vai ser explicado; 2) "construir entidades" - elabora-se uma introdução aos protagonistas da história e ao seu comportamento; 3) "transformar conhecimento" - implica uma elaboração das ideias, um clarificar e aprofundar de ideias; como resultado esse tipo de explicação é difícil de compor, tornado o texto mais denso no decorrer do discurso; e 4) "atribuir significado ao que é material" - visa ilustrar como o mundo físico se comporta da maneira explicada). É de notar que, embora o trabalho de OGBORN et al. (1996) tenha emergido no contexto da sala de aula de ciências, essa conceptualização tem vindo a ser usada, com sucesso, por vários autores para a análise de explicações científicas em textos (TURNER, 2004; AFONSO; GILBERT, 2013). Desse modo, a análise macro do texto consistiu na aplicação da técnica de análise de conteúdo de Bardin (2014), consubstanciada nas categorias de Scott (1988) e de Ogborn et al. (1996), acima descritas. Essa análise de conteúdo foi, num primeiro momento, realizada individualmente pelos dois autores do presente texto, seguida da comparação das análises efetuadas. Após essa análise macro, guiada pelos estudos de Scott (1988) e Ogborn et al. (1996), procedeu-se a uma análise micro do texto. Essa análise micro teve em consideração que a análise de um texto deve ser vista como um processo suficientemente aberto e flexível de modo a poder ser reestruturado durante o processo de aplicação (HOWARTH, 2000), o qual pode ser aperfeiçoado por intermédio do diálogo entre teorias de Fairclough (2003).

Neste sentido, como refere Fairclough (2003), a análise do texto não pode efetuada pela aplicação de um sistema de categorias vistas como autônomas. Tendo em conta esses pressupostos, para a análise micro do texto efetuou-se uma análise do discurso (FAIRCLOUGH, 2003), tendo-se procurado no texto do livro didático, e em particular em cada um dos elementos das narrativas, marcas linguísticas (por exemplo, léxico, estruturas de coesão, ou metáforas conceptuais), de modo a inferir o discurso usado na construção destes elementos e a conceptualização do leitor veiculada. Este último aspeto foi baseado no trabalho de Nascimento e Martins (2005). Essa análise foi, num primeiro momento, efetuada por um dos autores do estudo com experiência nesse tipo de análise (AFONSO; AFONSO; RODRIGUES, 2019), tendo sido partilhada e discutida com o outro autor do estudo de modo a resolver situações de entendimentos discrepantes. 


\section{Resultados}

\section{As narrativas sobre termodinâmica}

A análise dos textos do capítulo de termodinâmica, a um nível macro, permite constatar que ambos os capítulos são marcados por narrativas com uma linha conceptual. Os temas dessas narrativas são apresentados nos títulos das diferentes seções e subseções do capítulo, todas elas com designações científicas. Ao passo que os títulos das seções são retirados dos programas ("Trabalho e energia termodinâmica" e "Leis da termodinâmica"); os títulos das subsecções, e, portanto, o modo como os conteúdos programáticos são estruturados, nem sempre são os mesmos nos dois capítulos. Destaca-se uma organização diferente dos conteúdos programáticos na seção "Leis da termodinâmica" dos dois capítulos (Quadro 3). A análise do Quadro 3 permite constatar que, ao contrário de Arieiro e Leitão (2015), autoras do livro didático 1 (LD1), Fernandes, Magalhães e Oliveira (2016), autores do livro didático 2 (LD2) introduzem mais duas subsecções na seção "Leis da termodinâmica": "aplicação da $1 .^{\mathrm{a}}$ Lei da termodinâmica aos processos adiabáticos e aos isoprocessos" e "Máquinas térmicas e máquinas frigoríficas”. Estas duas subseções veiculam relações entre a termodinâmica e a sociedade.

Quadro 3- Subseções da seção "Leis da termodinâmica"

\begin{tabular}{|c|c|c|}
\hline Subsecções & LD 1 & LD 2 \\
\hline $1^{\mathrm{a}}$ Lei da termodinâmica & $\sqrt{ }$ & $\sqrt{ }$ \\
\hline Aplicação da $1^{\text {a }}$ Lei da termodinâmica aos processos adiabáticos e aos isoprocessos & & $\sqrt{ }$ \\
\hline $2^{a}$ Lei da termodinâmica e entropia & $\sqrt{ }$ & $\sqrt{ }$ \\
\hline Máquinas térmicas e máquinas frigoríficas & & $\sqrt{ }$ \\
\hline Lei Zero da termodinâmica & $\sqrt{ }$ & $\sqrt{ }$ \\
\hline
\end{tabular}

Fonte: Dados da pesquisa.

Também a configuração das páginas dos capítulos dos livros reflete o enfoque conceptual das narrativas quando se apresentam as seguintes estruturas de didatização do conteúdo: ideias científicas fundamentais realçadas no corpo do texto; conceitos científicos inseridos na margem do texto em caixas de texto, algumas designadas por "ideias chave" ou "nota"; glossários de ideias científicas apresentados no final de algumas seções do capítulo, sendo designadas de "relembra o que aprendeste"; e mapas de conceitos no final do capitulo de termodinâmica. É de notar que as estruturas de didatização se encontram mais presentes no texto de termodinâmica do LD2 do que do LD1. De fato, das estruturas de didatização inumeradas, o texto de termodinâmica do LD1 apenas recorre ao realce de ideias fundamentais no corpo do texto. Quanto aos elementos que compõem as narrativas com um enfoque conceptual, constata-se que estes são mais diversificados no capítulo de termodinâmica do LD2 do que do LD1. As narrativas sobre termodinâmica presentes no LD2 são construídas com recurso aos elementos: "construir entidades", "transformar conhecimento", e "atribuição de significação ao que é material" e, embora pouco presente, encontra-se também o elemento "criar diferenças”. Nas narrativas 
sobre termodinâmica do LD1, incluem-se momentos nos quais se "constroem entidades" e, por vezes, momentos nos quais "se transforma conhecimento". Contudo, os restantes elementos estão frequentemente ausentes. A título de exemplo, considere-se como a narrativa sobre condução térmica se desenvolve no LD1 e no LD2 (excerto A e excerto B, respectivamente). Os autores dos excertos iniciam o assunto "formas de transferência de energia" de forma semelhante, isto é, designado os fenômenos: "condução" e "convecção". Uma vez identificado o assunto em estudo, os autores optam por diferentes formas de o desenvolver. Como se pode constatar pelo excerto B, a questão inicialmente colocada ao aluno dá ao leitor a oportunidade de elaborar uma resposta e de, posteriormente, a confrontar com o texto apresentado pelos autores. Essa oportunidade de "criar diferenças" entre o pensamento do aluno e as ideias científicas não surge no excerto A. Nos excertos A e B, a narrativa constrói-se com a apresentação dos protagonistas da história: as partículas e os seus comportamentos com o aumento da temperatura. Contudo, apenas no excerto B, a narrativa prossegue com o elemento "transformar entidades". Esse elemento da narrativa permite esclarecer e aprofundar as ideias inicialmente veiculadas, fazendo uso do conceito de energia cinética, da sua transferência num sistema e da sua relação com a dimensão submicroscópica. Toda essa explicação é contextualizada com recurso a um exemplo do dia a dia, o aquecimento de uma barra metálica numa chama, o que permite aos alunos a "atribuição de significação ao que é material". Por outro lado, no excerto A os autores terminam a narrativa apresentando uma situação na qual se verifica a condução de calor, mas sem explicar como é que ela ocorre nesta situação específica.

\begin{abstract}
Excerto A - LD1
0 processo de transferência de energia como calor pode ocorrer através de duas formas distintas, a condução e a convecção. No processo de condução térmica, a energia é transferida por interacções, a nível microscópico, das partículas constituintes do sistema. As partículas do sistema que recebem energia agitam-se mais, propagando-se essa agitação às outras partículas. As partículas do meio material agitam-se, mas afastam-se pouco das suas posições de equilíbrio [...]. A condução térmica ocorre numa barra metálica que é aquecida. (ARIEIRO; LEITÃo, 2015, p. 82).
\end{abstract}

\title{
Excerto B - LD2
}

Existem fundamentalmente duas formas de propagação de energia sob a forma de calor: a condução e a convecção. Se segurarmos uma ponta de uma barra metálica e colocarmos a outra ponta a aquecer numa chama, rapidamente constataremos que a ponta que seguramos começa a aquecer. Como é que tal acontece? A matéria é constituída por partículas que se encontram em permanente movimento. A velocidade das partículas e das vibrações é tanto maior quanto maior for a temperatura do sistema. Estamos na presença de dois sistemas - neste caso, a chama e a barra metálica - que entram em contacto. As partículas do sistema com maior temperatura, a chama, têm maior energia. Esta energia é transferida por colisões para as partículas que se encontram na barra, que a vão propagar no seu interior. De igual modo, se uma parte do sistema ficar mais quente, as partículas dessa região vão ficar momentaneamente com maior energia cinética que do que as da sua vizinhança, pelo que parte dessa energia vai ser transferida, ao longo de todo o sistema, através de colisões. No entanto, as partículas não se deslocam de um 
ponto para o outro do sólido. À transferência de energia feita deste modo chama-se condução. (FERNANDES; MAGALHÃES; OLIVEIRA, 2016, p.109).

A preocupação em inserir nas narrativas o elemento "atribuição de significação ao que é material” é maior no LD2 do que no LD1. Nas narrativas do LD2, esse elemento, referente à aplicação dos conteúdos de termodinâmica abordados a situações do dia a dia ou à biografia de um cientista, encontram-se muitas vezes em caixas de texto desligadas do texto principal e com o título "saber mais..." ou "sabias que...". De modo semelhante, o elemento "criar diferenças" encontra-se quase ausente das narrativas do LD1, tendo apenas sido identificado na subseção "Introdução". Nessa seção, esse elemento tem como finalidade cativar o leitor para o interesse da termodinâmica. Fá-lo expondo o objeto de estudo da termodinâmica a partir da resposta a duas questões que se encontram implícitas no texto - "0 que é a termodinâmica?”, "Qual o seu objeto de estudo" (Excerto C).

Excerto C - LD1

A Termodinâmica é o ramo da física que estuda os fenômenos térmicos.

A termodinâmica efetua o seu estudo por duas vias:

- a da Termodinâmica Clássica - baseada na observação dos fenômenos à escala macroscópica;

- a da Mecânica Estatística - baseada na teoria cinético-molecular e que interpreta os fenômenos a nível microscópico.

As leis da Termodinâmica são de natureza experimental. Os sistemas termodinâmicos são constituídos por muitas partículas. (ARIEIRO; LEITÃO, 2015, p. 80).

A parca presença desse elemento no capítulo de termodinâmica do LD1 contrasta com a sua presença, embora também pouco frequente, no capítulo de termodinâmica do LD2. Tal como no LD1, o elemento "criar diferenças" surge na seção "Introdução", mas ao responder a um maior número de questões - "0 que influenciou o desenvolvimento da termodinâmica?", "Porque é importante a termodinâmica?", "0 que é a termodinâmica?", "Qual o seu objeto de estudo? (Excerto D) - apresenta um maior poder persuasor do que a "Introdução" inserida no LD1.

Excerto D - LD2

A invenção da máquina a vapor [Fig. 1] contribuiu de forma decisiva para o aparecimento de um ramo da Física que nos permite interpretar muitos fenómenos que ocorrem no mundo que nos rodeia como os descritos acima e tirar proveito desse conhecimento. Este ramo da Física chamase Termodinâmica e estuda as transferências de energia entre sistemas com um grande número de partículas. A Termodinâmica não se interessa por partículas individuais, mas sim pelo conjunto delas, os corpos macroscópicos, observáveis e com propriedades mensuráveis. Podemos também dizer que na Termodinâmica se estudam fenómenos térmicos, onde é importante considerar a temperatura dos sistemas. (FERNANDES; MAGALHÃES; OLIVEIRA, 2016, p. 102).

Para além das questões colocadas ao leitor, os autores do LD2 recorrem ao diferente significado entre conceitos na linguagem do dia a dia e na linguagem científica (por 
exemplo, de calor e de temperatura) para introduzir o elemento "criar diferenças" nas narrativas com uma linha conceptual (Excerto E).

\begin{abstract}
Excerto E - LD2
Embora a palavra calor seja intuitiva para nós, temos a tendência para lhe atribuir o mesmo significado que à palavra temperatura. Estas palavras definem grandezas diferentes. Enquanto a temperatura é uma grandeza que é propriedade dos sistemas, o calor é a energia transferida entre sistemas devido a uma diferença de temperatura entre eles. (FERNANDES; MAGALHÃES; OLIVEIRA, 2016, p. 108).
\end{abstract}

Embora escassas, foram encontradas nos textos de termodinâmica do LD1 e do LD2 narrativas com uma linha epistemológica. Essas narrativas, construídas com recurso a marcos históricos, veiculam ideias científicas atualmente aceitas. No capítulo de termodinâmica do LD1 a única narrativa com uma linha epistemológica refere-se ao trabalho de Joule sobre equivalência entre trabalho e calor (excerto F); no capítulo de termodinâmica do LD2, para além de uma narrativa sobre o mesmo trabalho de Joule, inclui-se ainda uma narrativa sobre Carnot e máquinas térmicas (excerto G) no corpo do texto. Apenas nesta última narrativa é apresentada uma breve referência ao contexto histórico, ao ser mencionada a razão que levou Carnot a refutar a convicção de que era possível construir uma máquina térmica ideal. Deste modo, a narrativa inicia-se com a "criação de diferenças" entre as ideias aceitas na época e as ideias de Carnot. 0 cerne de todas as narrativas com uma linha epistemológica consiste na descrição de algumas ferramentas usadas (experiências realizadas, caso de Joule, ou as experiências pensadas, caso de Carnot) para a construção do modelo científico que se pretende veicular.

\title{
Excerto F - LD1
}

No século XIX, James P. Joule (1818-1889) estabeleceu a equivalência entre calor e o trabalho ao observar que para aquecer um líquido dentro de um recipiente tanto podia usar calor como trabalho, pois ambos os processos permitiam aumentar a energia interna do líquido. Esta equivalência foi estabelecida após Joule realizar a seguinte experiência: num vaso calorimétrico (recipiente de paredes termicamente isoladoras) contendo água colocou um agitador formado por uma série de palhetas ligado a um veio que podia executar um movimento de rotação. 0 movimento das palhetas era accionado pela queda de um corpo, de massa $\mathrm{M}$, preso a um fio. À medida que o corpo caia, a água exercia forças sobre as palhetas que rodavam estas forças realizavam trabalho dissipativo e a água ia aquecendo. 0 aumento da temperatura do sistema foi confirmado num termómetro, colocado previamente no recipiente [...]. Calor e trabalho são maneiras distintas de transferir energia. Transferir energia como calor corresponde à realização de trabalho microscópico. (ARIEIRO; LEITÃO, 2015, 84).

\section{Excerto G - LD2}

Até meados do século XIX, acreditava-se ser possível a construção de uma máquina térmica ideal, que seria capaz de transformar toda a energia fornecida na forma de trabalho, obtendose um rendimento de 100\%. Carnot, um engenheiro francês, para demonstrar que tal não seria possivel, propôs uma máquina com rendimento de $100 \%$, propôs uma máquina térmica teórica 
que se comportava como uma máquina ideal, estabelecendo um ciclo que é tido como o ciclo mais eficiente de uma máquina térmica e definido de acordo com as leis da termodinâmica. Mais tarde, este ciclo passou a ser chamado de ciclo de Carnot. Para obter o máximo rendimento, Carnot definiu este ciclo termodinâmico ideal como um ciclo reversível (não envolve aumento da entropia), composto por quatro processos: dois processos isotérmicos e dois processos adiabáticos [...]. (FERNANDES; MAGALHÃES; OLIVEIRA, 2016, p. 139).

No caso da narrativa sobre o rendimento de uma máquina térmica (excerto G), esta termina com a apresentação de relações entre o trabalho de Carnot e áreas de inovação atuais, como, por exemplo, indústria de máquinas térmicas (excerto H). Deste modo, ocorre "a atribuição de significação ao que é material"

\section{Excerto H - LD2}

[...] verifica-se ainda que qualquer máquina térmica reversível (ideal) a operar entre as temperaturas $\mathrm{Tq}$ e $\mathrm{Tf}$ tem um rendimento máximo possível que pode ser obtido através do rendimento estabelecido para o ciclo de Carnot. Este dado é muito útil, em termos práticos, quando se projecta a construção de uma máquina, apesar de sabermos que o valor real será sempre inferior ao obtido. (FERNANDES; MAGALHÃES; OLIVEIRA, 2016, p. 139).

No capítulo de termodinâmica de LD2 é ainda possível encontrar, em caixas nas margens da página e desligadas do corpo do texto, narrativas com uma linha conceptual nas quais se apresenta a biografia e o contributo de algumas personalidades históricas para a termodinâmica. É o caso de Rudolf Clausius e de Nicolas Léonard Sadi Carnot.

\section{A linguagem das narrativas}

A análise das narrativas a um nível micro permite constatar que nestas o discurso científico se encontra bem marcado. Assim, faz-se uso de um léxico denso inserido em estruturas complexas (subordinação), acompanhadas de uma linguagem simbólica e, por vezes, de uma linguagem científica no modo gráfico. Os excertos E e $\mathrm{F}$, referentes à aplicação da $1^{\text {a }}$ Lei da Termodinâmica, ilustram como esse discurso científico é usado.

\section{Excerto E - LD1}

Num processo adiabático não ocorre transferência de calor entre o sistema e a vizinhança $(Q=0)$, tal ocorre quando o sistema está termicamente isolado ou, então, se o processo é realizado rapidamente. É o que acontece, por exemplo, quando se enche o pneu de uma bicicleta. A 1. ${ }^{a}$ Lei da termodinâmica aplicada a um processo adiabático é traduzida pela expressão:

(supõe-se $\mathrm{R}=0$ )

Se o sistema sofre uma compressão adiabática (é o que acontece no exemplo anterior), o exterior realiza trabalho sobre o sistema (gás), e a energia interna do gás aumenta, o que se manifesta macroscopicamente pelo aumento da temperatura. Numa expansão adiabática de um gás ideal, a energia interna não varia, é função exclusiva da temperatura (ARIEIRO; LEITÃ̃, 2015, p. 92). 
Excerto F - LD2

Num processo isocórico o volume não varia. Como o volume é constante, $\Delta V=0$, não há realização de trabalho. Este é um processo fácil de conseguir, já que basta que o sistema tenha paredes seladas que não sofram expansão ou contracção de volume. Se aplicarmos a $1 .^{a}$ Lei da Termodinâmica, temos que: $\Delta \mathrm{U}=\mathrm{Q}+\mathrm{W}$. Como $\mathrm{W}=-\mathrm{px} \Delta \mathrm{V}$, onde $\Delta V=0$, então $W=0$.

Assim: $\Delta U=Q$.

A representação de uma isocórica, num gráfico de pressão em função do volume, corresponde a uma linha recta vertical [Fig.17].

17 Representação gráfica de um processo isocórico.

\section{Figura 1}

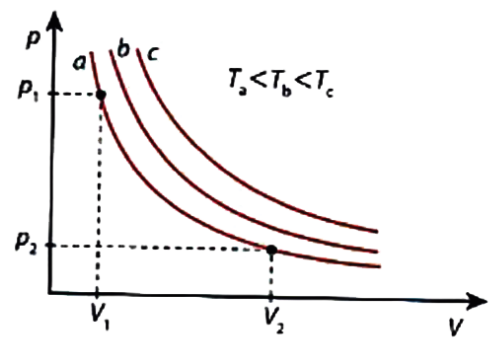

Fonte: (FERNANDES; MAGALHÃES; OLIVEIRA, 2016, p. 124).

Uma análise do discurso dos textos do LD1 e do LD2 permite constatar que os textos do capítulo do LD1 apresentam um estilo expositivo (como vimos no excerto E). No caso das narrativas de termodinâmica do capítulo do LD2, o seu estilo varia entre o expositivo (excerto F) e o estilo narrativo (excerto G). No capítulo do LD2, o estilo narrativo, embora se encontre em narrativas inseridas no corpo do texto, é o estilo escolhido pelos autores para escreverem os textos complementares que se encontram nas seções "saber mais" ou "sabias que" (excerto G).

Excerto G - LD2

Como surgem as brisas maritimas?

É também devido a grandes massas de água que são criadas as brisas terrestres e marítimas junto às costas. Junto ao mar, nas horas de maior intensidade da radiação solar, o aumento da temperatura do solo é grande e, por isso, o ar aquece e sobe. 0 ar sobre a água permanece fresco, devido à elevada capacidade térmica mássica da água, e desloca-se em direcção à terra, criando assim uma brisa marinha diurna. De noite, o solo arrefece muito, enquanto a água, com maior capacidade térmica mássica, arrefece pouco. 0 ar fresco da terra dirige-se para a água criando assim a brisa terrestre nocturna. Estas brisas são na verdade correntes de convecção geradas devido a diferenças de temperatura. (FERNANDES; MAGALHÃES; OLIVEIRA, 2016, p. 113). 
Nesses textos com estilo narrativo, o discurso é marcado por uma linguagem híbrida, isto é, na qual a linguagem específica e não específica da ciência se articulam, e no qual se incluem questões para guiar o leitor. Essa linguagem híbrida contrasta com o discurso científico que marca as narrativas do texto do LD1. Considere-se, por exemplo, a linguagem usada nos capítulos de termodinâmica do LD1 e do LD2 para veicular o conceito de capacidade térmica mássica (excerto H do LD1 e I do LD2). Ao contrário do excerto $\mathrm{H}$, no excerto I os autores recorrem frequentemente ao uso de metáforas, incluem a sua "voz" e usam questões. Assim, ao invés de se quantificar a capacidade térmica mássica da água, utilizam-se expressões como "muito elevado" ou "capacidade elevada"; empregam-se metáforas, tais como "a água actua”, juntamente com vocabulário próprio da termodinâmica, por exemplo, "capacidade térmica mássica", "energia"; escolhese a primeira pessoa do plural ("Assim, verificamos", "se repararmos”, "convém agora refletirmos", "utilizaremos a seguinte convenção"); e inclui-se uma questão na narrativa ("Mas como determinar a quantidade de calor, isto é, a energia transferida entre sistemas a diferentes temperaturas?”).

Excerto H - LD1

A variação de energia interna de um sistema pode ser detectada macroscopicamente por uma variação de temperatura ou por uma mudança de estado durante a qual a temperatura permanece constante. Cada material comporta-se de modo diferente quando é sujeito a aquecimento. A capacidade térmica mássica é uma grandeza física que caracteriza termicamente cada material. Por exemplo, a capacidade térmica mássica da água líquida é:

$\mathrm{C}_{\text {água }}=4,18 \mathrm{Jg}^{-1} \mathrm{C}^{-1}=4,18 \times 103 \mathrm{Jkg}^{-1} \mathrm{C}^{-1}$

Este valor significa que são necessários 4,18 joules para elevar de 1grau Celsius a temperatura de 1 grama de água [...]. Quando se aquece um sistema a pressão constante, verifica-se experimentalmente que a energia transferida como calor, $Q$, é proporcional à variação da temperatura do corpo, $\Delta \mathrm{T}$ :

$\mathrm{Q}=\mathrm{m}$ c $\Delta \mathrm{T}$

Onde m é a massa do corpo e c a capacidade térmica mássica da substância que o constitui. (ARIEIRO; LEITÃO, 2015, p. 83).

Excerto I - LD2

Já sabemos como determinar o trabalho realizado por um sistema. Mas como determinar a quantidade de calor, isto é, a energia transferida entre sistemas a diferentes temperaturas? Consideremos o seguinte: sabemos que ao aquecermos $1 \mathrm{~kg}$ de água é necessário fornecer 4186 $\mathrm{J}$ para elevarmos a sua temperatura de $1^{\circ} \mathrm{C}$. Se tivermos $2 \mathrm{~kg}$ precisamos do dobro da energia. E se pretendermos elevar de $2^{\circ} \mathrm{C}$ a temperatura de $1 \mathrm{~kg}$ de água precisamos também do dobro da energia. Verificamos assim que a quantidade de calor, ou seja, a energia transferida para um sistema é diretamente proporcional à massa do sistema e à sua variação de temperatura. No entanto, se em vez de água tivermos uma barra de ferro de $1 \mathrm{~kg}$, a energia necessária para elevar a sua temperatura de $1^{\circ} \mathrm{C}$ é de $448 \mathrm{~J}$. Portanto, a quantidade de calor depende do material 
em causa. A quantidade de calor vai assim depender também da capacidade térmica mássica, c, característica de cada material. E que é a constante de proporcionalidade.

Quantidade de calor e variação de temperatura de um sistema

A quantidade de calor que provoca uma variação de temperatura num sistema é directamente proporcional à massa do sistema e à sua variação de temperatura. A constante de proporcionalidade é a capacidade térmica mássica, uma característica de cada material.

[...] na tabela podemos verificar que a água tem um valor de capacidade térmica mássica muito elevado quando comparado com o de outras substâncias. Isto significa que a água tem uma capacidade elevada de absorver energia, ao aquecer, podendo também libertar muita energia ao arrefecer. Devido a este facto, a água actua, em muitas regiões, como reguladora do clima. (FERNANDES; MAGALHÃES; OLIVEIRA, 2016, p. 111).

Do modo semelhante, apenas no texto do capítulo de termodinâmica do LD2 são apresentadas ilustrações híbridas, isto é, representações nas quais códigos de representação usados em Física, tais como, vetor para representar a velocidade, são usados em simultâneo com códigos de representação criados pelo autor, como é o caso das curvas para representar a energia potencial entre partículas. Um exemplo desse tipo de representação encontra-se na figura 2.

\section{Figura 2}
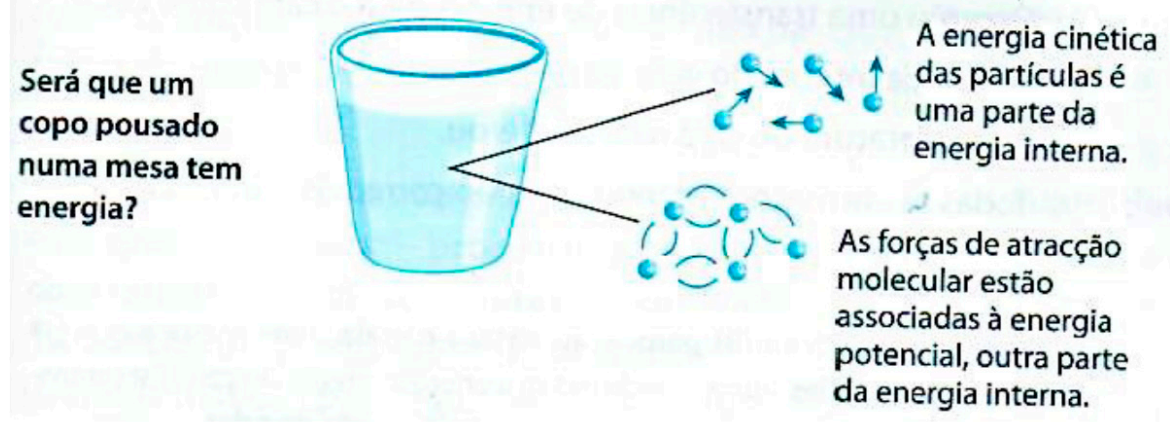

Fonte: (FERNANDES; MAGALHÃES; OLIVEIRA, 2016 p. 117).

\section{A conceptualização do leitor pelos autores}

Os capítulos analisados estão incluídos nos livros didáticos do aluno, pelo que é esperado que os alunos da $10^{\text {a }}$ classe sejam os destinatários. A análise da estrutura dos capítulos de termodinâmica, das suas narrativas e do discurso dos seus textos indica 
que leitores do capítulo de termodinâmica são conceptualizados de modos diferentes em LD1 e em LD2. 0 capítulo de termodinâmica do LD1 constitui uma espécie de súmula das principais ideias sobre termodinâmica, as quais se esperam que os alunos retenham: não são apresentados textos complementares, no final de cada subseção é, geralmente, apresentado um exercício resolvido, e no final de cada seção um elevado número de exercícios para resolver. Como já referido, há um enfoque nas narrativas com uma linha conceptual, nas quais raramente estão presentes os elementos "criar diferenças" e “atribuição de significação ao que é material”. Não existe uma preocupação em aprofundar ou clarificar conceitos chave, uma vez que o elemento "transformar conhecimento" também não é muito frequente. As narrativas são escritas num estilo expositivo, com recurso a frases curtas e ao discurso científico. Esse discurso científico é apresentado na forma verbal e gráfica e os gráficos apresentados nem sempre são explicados no corpo do texto. Essas características sugerem que o capítulo de termodinâmica do LD1 se destina a um leitor que possui conhecimentos científicos e que se encontra familiarizado com a linguagem multimodal usada em termodinâmica, sendo, por isso, capaz de descodificar os códigos de representação usados nos gráficos ou distinguir os significados de palavras usadas no dia a dia e no contexto científico (por exemplo, calor). Em suma, o enfoque é na aquisição de conhecimentos científicos chaves, necessários para a resolução de exercícios.

0 capítulo de termodinâmica do LD2 também apresenta um enfoque nas narrativas com uma linha conceptual, mas a estruturação deste capítulo, os elementos presentes nas narrativas e o seu discurso indicam que o leitor é conceptualizado de modo diferente do leitor do capítulo de termodinâmica do LD1. De fato, o capítulo de termodinâmica do LD2 inclui várias estruturas de didatização e é frequente o uso de caixas de texto nas margens das páginas com os termos "palavras-chave", "relembra”, "nota”, "recordar", "sabias que”. Por exemplo, o verbo "relembrar", no imperativo, é destacado na margem da página e remete para fórmulas matemáticas (a pressão de um gás) ou para teorias e modelos (teoria cinético-molecular). Também no corpo do texto, os autores do LD2 procuram que o leitor recorde conhecimentos prévios "recordemos que, em física, trabalho é a energia transferida entre sistemas devido à acção de uma força” (FERNANDES; MAGALHÃES; OLIVEIRA, 2016, p. 105) ou "como também já sabemos, a energia cinética está associada ao movimento dos sistemas" (FERNANDES; MAGALHÃES; OLIVEIRA, 2016, p. 117). Tais marcas indicam que o leitor é alguém com conhecimentos científicos prévios. Para além disso, o estilo expositivo em várias narrativas com uma linha conceptual e a presença frequente do elemento "transformar conhecimento" em muitas delas perspetivam um leitor fluente, capaz de compreender o tratamento aprofundado das ideias científicas. Por outro lado, a existência de narrativas escritas com um estilo narrativo, com recurso a uma linguagem (verbal e gráfica) híbrida, sugere um leitor que ainda se encontra num processo de enculturação da linguagem científica. É, ainda, esperado um leitor intrinsecamente motivado para o estudo do tema, dada a pouca frequência do elemento "criar diferenças" nas narrativas. A existência de algumas narrativas com uma linha epistemológica no capitulo de termodinâmica do LD2 que, por vezes, culminam com a relevância dos modelos construídos no passado (ciclo de Carnot) para áreas de inovação atual, como, por exemplo, na indústria, parece indicar a necessidade de familiarizar o leitor com potenciais áreas de 
trabalho futuro. Embora exista no capítulo de termodinâmica do LD2 alguns textos nos quais os conhecimentos apresentados são relacionados com o dia a dia - funcionamento de um planador, o clima marítimo como mais ameno que o continental, funcionamento de um motor de um automóvel a gasolina, rendimento das máquinas térmicas atuais em nenhum dos casos essas relações estimulam explicitamente o exercício da cidadania. Em suma, o leitor do capítulo de termodinâmica do LD2 é conceptualizado como um leitor fluente, mas ainda em processo de enculturação com a linguagem científica, intrinsecamente motivado para o estudo do tema, mas a quem é necessário desenvolver a compreensão de conceitos sobre termodinâmica. Essa compreensão de conceitos tem a finalidade de lhes permitir não só resolver exercícios, mas também identificar situações do dia a dia nas quais a termodinâmica se encontra presente.

\section{Discussão}

Os resultados apresentados indicam que ambos os capítulos de termodinâmica em análise valorizam as narrativas com uma linha conceptual e nas quais o elemento "criar diferenças" se encontra pouco presente. Como resultado, o leitor é pouco orientado para perceber o interesse, a importância e a necessidade da abordagem dos assuntos de termodinâmica. Assume-se, assim, que o leitor não necessita de ser persuadido para acompanhar o desenrolar das narrativas presentes nos capítulos. 0 fato de existir uma elevada percentagem de crianças e jovens fora do sistema de ensino (48\%, de acordo com o Censo de 2014) e de a percentagem de jovens que se matriculam no II $^{\circ}$ ciclo do ensino secundário angolano ser reduzido (cerca de 30\%) (CEIC / UCAN, 2016), poderá criar a imagem de um aluno da $10^{\text {a }}$ classe com elevados níveis de motivação intrínseca para o estudo da física.

Apenas no capítulo de termodinâmica do LD2, as narrativas com uma linha conceptual incluem, frequentemente, o elemento "atribuir significação ao que é material". Este operacionaliza-se a partir de exemplos de aplicações práticas da termodinâmica ao dia a dia, sem se discutir ou se refletir sobre temas controversos ou desafios energéticos que a sociedade angolana enfrenta (GOMES, 2013; ANGOLA, 2018). Na verdade, as atividades práticas existentes resumem-se a exercícios resolvidos ou à resolução de exercícios. Ou seja, o enfoque dos capítulos de termodinâmica do LD1 e do LD2 é no conhecimento canônico da termodinâmica e na respetiva avaliação, sem se preocupar com o desenvolvimento de capacidades e de modos de pensar e agir sobre problemas reais relacionados com a energia no contexto angolano. Há, no entanto, que realçar que a finalidade de veicular esses conhecimentos parece ser diferente para os autores do LD1 e para os autores do LD2. No caso do LD1 os autores preocuparam-se em apresentar um resumo das principais ideias sobre termodinâmica, para que os alunos resolvam exercícios. No caso do LD2 os autores também se preocupam em que os alunos compreendam os assuntos de termodinâmica, desenvolvam a linguagem científica nesta área e percebam situações do dia a dia em que a termodinâmica se encontra presente. 0 uso de um estilo discursivo em muitas narrativas do LD2, que contrasta com o estilo expositivo das narrativas do LD1, traduz uma preocupação com a transformação do conhecimento científico numa versão compreensível pelo leitor 
(GRAESSER; LEON; OTERO, 2002). 0 enfoque nas narrativas com uma linha conceptual em ambos os capítulos poderá ter várias explicações. Primeiro, a construção dos capítulos de termodinâmica com base no programa de física para a $10^{\text {a }}$ classe o qual, por ser anterior à atual LBSEE, não contempla a formação do cidadão. Segundo, a potencial pouca familiaridade dos autores, de nacionalidade Portuguesa, com contextos angolanos relevantes para a abordagem da termodinâmica. Terceiro, as pressões do discurso do setor econômico que exigem a formação de recursos humanos para as profissões de "cientista" e de "engenheiro" (NZAU, 2010). Quarto, a percepção dos autores sobre os professores de física angolanos - deficiente formação e uso extensivo do livro didático para estruturar as suas aulas - poderá ter resultado na adoção de um livro didático consistente com a visão I do currículo de Roberts (2011), por esta ser mais fácil de operacionalizar pelos professores (ROBERTS, 2011).

0 fato de os capítulos de termodinâmica não apresentarem sugestões metodológicas relevantes, que contribuam para a formação do cidadão angolano, requer que os professores enriqueçam as suas aulas de modo a ajustar o seu ensino com a cultura e experiências locais e necessidades regionais e nacionais (SILVA, 2011). Contudo, a deficiente formação de muitos professores de física angolanos e o excesso de alunos por turma (NZAU; LOPES; COSTA, 2012) condicionam a adoção de metodologias consistentes com a discussão de ideias socialmente relevantes (NZAU, 2018). 0 enfoque nos conhecimentos canônicos da ciência nos livros didáticos e o seu texto hermético foi também encontrado noutros estudos, designadamente nos livros didáticos (para alunos de 15-18 anos) da Zâmbia (MUMBA; CHABALENGULA; HUNTER, 2006; MUMBA; HUNTER, 2009). Essa estrutura discursiva sugere que existe pouco espaço para a mudança em direção a uma visão de transformação da educação. Embora escassas, foram encontradas algumas narrativas com uma linha epistemológica no corpo do texto de ambos os capítulos de termodinâmica. Estas narrativas representam marcos históricos no desenvolvimento da termodinâmica, descrevem os procedimentos para a construção de modelos científicos e têm o propósito de veicular ideias científicas atualmente aceitas de modo a torná-las memoráveis (MATTHEWS, 1994). Para além dessas narrativas com uma linha epistemológica, o capítulo do LD2 inclui outras em caixas na margem dos textos e nas quais se apresenta a biografia de um cientista, ou o seu contributo para a termodinâmica. Embora tais narrativas contribuam para humanizar a ciência, podendo ser vistas como um elemento de motivação (MATTHEWS, 1994), a sua não integração no corpo do texto poderá indicar que a sua importância é secundária (JUSTI, 2000).

No que se refere ao modo como os autores dos livros didáticos conceptualizam os leitores dos capítulos de termodinâmica, constata-se que esta conceptualização não é mesma para ambos os autores. Assim, ambos assumem que os alunos são fluentes em língua portuguesa, mas a maior complexidade das frases incluídas no LD2, em relação ao LD1, poderá indicar que para os autores do LD2 os alunos possuem um nível mais elevado de domínio da língua portuguesa. De fato, embora o português seja a língua oficial e de ensino, esta é a língua materna de apenas cerca de 30\% da população, a qual se encontra em meios urbanos (GASPAR, 2015). Acresce ainda que os alunos que ingressam na $10^{\text {a }}$ classe constituem uma minoria no contexto angolano, no qual existe 
uma elevada taxa de abandono escolar (CEIC / UCAN, 2016) razão pela qual os autores dos livros didáticos poderão assumir que estes se destinam a uma "elite". Para além disso, o fato de o capítulo estar marcado por narrativas com uma linha conceptual, poderá ter subjacente a representação do aluno como um "pré especialista" e a necessidade de o preparar para o mercado de trabalho. Contudo, os autores do capítulo do LD1 parecem assumir que esse "pré especialista" é capaz de compreender a linguagem científica, e que se encontra intrinsecamente motivado para o estudo da termodinâmica. Por outro lado, para os autores do capítulo de termodinâmica do LD2, esse "pré especialista” encontra-se ainda num processo de enculturação com a linguagem científica, sendo necessário desenvolver a compreensão de conceitos sobre termodinâmica e, por vezes, sustentar o seu interesse, por exemplo a partir da biografia de personalidades na história da termodinâmica ou de exemplos do dia a dia em que a termodinâmica é aplicada. Por outro lado, a não inclusão nos livros didáticos das diretrizes internacionais para o ensino das ciências (OCDE, 2016) poderá refletir a percepção dos autores sobre o elevado capital científico (ARCHER et al., 2015) dos alunos do II $^{\circ}$ ciclo do ensino secundário geral, quer pelo acesso à informação em contextos culturais científicos (através da Internet ou de museus), quer pelas suas redes sociais (contatos com engenheiros). Essas redes sociais poderão constituir um recurso para que os alunos discutam assuntos atuais controversos, com dimensão local, regional ou nacional, e nos quais a termodinâmica se encontra presente.

\section{Conclusão}

Este estudo procurou analisar o modo como os capítulos de termodinâmica, dos livros didáticos de física angolanos para a $10^{\text {a }}$ classe, veiculam uma relação entre o conhecimento científico e o posicionamento do indivíduo na sociedade sobre questões energéticas. A análise efetuada, centrada na análise dos textos dos capítulos no contexto sócio cultural em que decorre, parece indicar a pouca preocupação dos autores dos livros didáticos em desenvolver nos alunos competências de pensar e agir sobre questões científicas atuais relacionadas com temas energéticos da sociedade angolana ou do mundo globalizante em que vivemos. Os capítulos enfatizam o conhecimento canônico da termodinâmica e a respectiva avaliação. De fato, embora existam estruturas de didatização do conteúdo, em especial no capítulo de termodinâmica do LD2, que refletem o discurso pedagógico, o discurso científico encontra-se fortemente vincado no texto, mas não só; o antigo discurso político e o discurso econômico angolano encontram-se também presentes. Estes últimos sobrepõem-se aos discursos atuais sobre políticas educativas angolanas e sobre educação em ciências defendidos no mundo ocidental. Os resultados deste estudo sugerem a necessidade de se repensar as narrativas presentes no capítulo de termodinâmica e o modo como o leitor é conceptualizado. Esse repensar terá que passar por uma reestruturação da estrutura do currículo e do programa de física para a $10^{\text {a }}$ classe, bem como das equipes que elaboram os livros didáticos. Estas equipes deveriam incluir autores familiarizados com as tendências atuais no ensino da física, com o contexto angolano e deveriam articularse com equipes preparadas para a formação de professores angolanos. Esse é um projeto ambicioso que exige um financiamento superior àquele que o governo angolano pode 
disponibilizar, pois requer ajudas internacionais (FIGUEIRA; INÁCIO, 2012). Essas ajudas são essenciais, por exemplo, para recrutar recursos humanos de países de expressão portuguesa e com elevado nível de formação da área da educação em física e que possam colaborar com os especialistas e professores angolanos.

\section{Referências}

AAC \& U. Association of American Colleges \& Universities. What is liberal education? Washington, D.C: AAC \& U, 2011. Disponível em: https://www.aacu.org/leap/what-is-liberal-education. Acesso em: jun. 2019.

AFONSO, Ana S.; GILBERT, John K. The role of 'Popular' books in informal chemical education. International Journal of Science Education, London, v. 3, n. 1, p. 77-99, 2013. Part B: Communication and Public Engagement.

AFONSO, Susana; AFONSO, Ana S.; RODRIGUES, Francisco. Towards an effective use of language to explain light in the museum. Science Education, New Jersey, v. 103, n. 4, p. 923-946, 2019.

AMARAL, Carmem Lúcia; XAVIER, Eduardo; MACIEL, Maria de Lourdes. Abordagem das relações ciência/ tecnologia/sociedade nos conteúdos de funções orgânicas em livros didáticos de química do ensino médio. Investigação em Ensino de Ciências, Porto Alegre, v. 14 n. 1, p. 101-114, 2009.

ANGOLA. Lei $n^{0}$ 17/16, de 7 de outubro de 2016. Institui a Lei de Bases do Sistema de Educação e Ensino (LBSEE). Luanda: [s. n.], 2016. Disponível em: http://www.ilo.org/dyn/natlex/docs/ ELECTRONIC/109840/136418/F1315876591/Untitled.FR12.pdf. Acesso em: jul. 2019.

ANGOLA. Plano de Desenvolvimento Nacional 2018-2022. Luanda: Ministério da Economia e Planeamento, 2018. Disponível em: https://www.ucm.minfin.gov.ao/cs/groups/public/documents/ document/zmlu/njax/ edisp/minfin601408.pdf. Acesso em: out. 2019.

ARCHER, Louise et al. Science capital: a conceptual, methodological and empirical argument for extending Bourdieusian notions of capital beyond the arts. Journal of Research in Science Teaching, Illinois, v. 52, n. 7, p. 922- 948, 2015.

ARIEIRO Maria E.; LEITÃO, Paula. Física 10ª classe. Luanda: Plural, 2015.

BARDIN, Laurence. Análise de conteúdo. 4. ed. Lisboa: Edições 70, 2014. Edição original: 1977.

BUENO DE ABREU, Teo.; FERNANDES, João Paulo.; MARTINS, Isabel. Levantamento sobre a produção CTS no Brasil no período de 1980-2008 no campo de ensino de ciências. Alexandria Revista de Educação em Ciência e Tecnologia, Florianópolis, v. 6, n. 2, p. 3-32, 2013.

BUZA, Juliana. Ensino de ciências em Cabinda/Angola: condições da prática docente, ideias de professores e desafios. Dissertação (Mestrado) - Universidade Federal do Pará, Belém, 2007.

CEIC / UCAN. Centro de Estudos e Investigação Científica da Universidade Católica de Angola. Relatório social de Angola 2016. Universidade Católica de Angola: Luanda, 2016. 
EUROPEAN COMISSION. Science education for responsible citizenship: Report to the European Commission of the expert group on science education. Bruxelas: European Comission, 2015. https:// op.europa.eu/en/publication-detail/-/publication/a1d14fa0-8dbe-11e5-b8b7-01aa75ed71a1

FAIRCLOUGH, Norman. Critical discourse analysis. London: Longman, 2003.

FERNANDES, Sofia; MAGALHÃES, Rui; OLIVEIRA, Ana. Física 10ª classe. Luanda: Plural, 2016.

FIGUEIRA, Santinho; INÁCIO, Eunice. Youth and adult learning and education in Angola. Osisa: DVV International, 2012.

GASPAR, Sofia Isabel Neves Fernandes. A língua portuguesa em Angola: contributos para uma metodologia de língua segunda. 2015. Dissertação (Mestrado) - Universidade Nova de Lisboa, Lisboa, 2015.

GILBERT, John. On the nature of context in chemical education. International Journal of Science Education, London, v. 28, n. 9, p. 957-976, 2006.

GOMES, Carla. 0 desafio da protecção ambiental em Angola. Revista de Direito Agroambiental e Teoria do Direito, Barreira, v. 1, n. 1, p. 13-34, 2013.

GRAESSER, Arthur, C.; LEON, josé A.; OTERO, José. Introduction to the psychology of science text comprehension. In: OTERO, José; LEON, josé A.; GRAESSER, Arthur C. (ed.). The psychology of science text comprehension. Mahwah: Erlbaum, 2002. p. 1-19.

HODSON, Derek. Science education as a call to action. Canadian Journal of Science, Mathematics and Technology Education, Ontario, v. 10, n. 3, p. 197-206, 2010.

HOWARTH, David. Discourse. Buckingham: Open University Press, 2000.

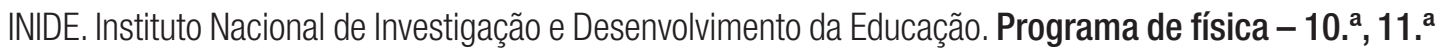
e 12. a classes: área de ciências físicas e biológicas. 2. ed.). Luanda: Moderna, 2014.

INIDE. Instituto Nacional de Investigação e Desenvolvimento da Educação. Plano curricular do pré-escolar e ensino primário. Luanda: Moderna, 2019.

JEGEDE, Olugbemiro. School science and the development of scientific culture: a review of contemporary science education in Africa. International Journal of Science Education, London, v. 19, n. 1, p. 1-20, 1997.

JUSTI, Rosaria. Teaching with historical models. In: GILBERT, John K; BOULTER, Carolyn J. (ed.). Developing models in science education. Dordrecht: Kluwer Academic, 2000. p. 209-226.

KÖVECSES, Zoltan. Metaphor: a practical introduction. Oxford: Oxford University Press, 2010.

MARTINS, Isabel. Analisando livros didáticos na perspectiva dos estudos do discurso: compartilhando reflexões e sugerindo uma agenda para a pesquisa. In: MARTINS, Isabel; GOUVÊA, Guaracira; VILANOVA, Rita (ed.). 0 livro didático de ciências: contextos de exigência, critérios de seleção, práticas de leitura e uso em sala de aula. Rio de Janeiro: [s. n.], 2012. p. 9-30. 
GREGORY, jane; MILLER, Steven. Science in Public: communication, culture, and credibility. New York: Plenum Press, 1998.

MARTINS, Isabel. Introdução. In: MARTINS, Isabel; GOUVÊA, Guaracira; VILANOVA, Rita (ed.). 0 livro didático de ciências: contextos de exigência, critérios de seleção, práticas de leitura e uso em sala de aula. Rio de Janeiro: FAPERJ/UFRJ/NUTES, 2012. p. 9-29.

MARTINS, Isabel. Quando o objeto de investigação é o texto: uma discussão sobre as contribuições da análise crítica do discurso e da análise multimodal como referenciais para a pesquisa sobre livros didáticos de ciências. In: NARDI, Roberto (org.). A pesquisa em Educação em ciências no Brasil: alguns recortes. São Paulo: Escrituras, 2007. p. 95-116.

MATTHEWS, Michael. Science teaching: the role of history and philosophy of science. New York: Routledge, 1994.

MEMBIELA, Pedro; PADILLA, Yolanda (ed.). Retos y perspetivas de la enseñanza de las ciencias desde el enfoque ciencia-tecnología-sociedad en Ios inicios del siglo XXI. Vigo: Educación, 2005.

MOREIRA, Maria Cristina; MARTINS, Isabel. A recontextualização de discursos da pesquisa em educação em ciências em livros didáticos de ciências: um estudo de caso. Revista Brasileira de Pesquisa em Educação em Ciências, Belo Horizonte, v. 15, n. 2, p. 237-257, 2015.

MOREIRA, Maria Cristina; PEREIRA, Marcus Vinicius; MARTINS, Isabel. Mecânica e educação para 0 trânsito: análise de um texto didático de ciências para o ensino fundamental. Revista Brasileira de Ensino de Física, São Paulo, v. 39, n. 4, p. e4403-1-e4403-7, 2017.

MUMBA, Frackson; CHABALENGULA, Vivien; HUNTER, William. A qualitative analysis of Zambian high school physics textbooks, syllabus and examinations for scientific literacy themes. Journal of Baltic Science Education, Siauliai, v. 2, n. 10, p. 70-76, 2006.

MUMBA, Frackson; HUNTER, William. Representative nature of scientific literacy themes in a high school chemistry course: the case of Zambia. Chemistry Education Research and Practice, Cambridge, v. 10, n. 30, p. 219-226, 2009.

NASCIMENTO, Tatiana Galieta; MARTINS, Isabel. 0 texto de genética no livro didático de ciências: uma análise retórica crítica. Investigações em Ensino de Ciências, Porto Alegre, v. 10, n. 2, p. 255-278, 2005.

NRC. National Research Council. A framework for K12 science education: practices, crosscutting concepts, and and core ideas. Washington, DC: The National Academy Press, 2012.

NZAU, Domingos K. Das concepções dos alunos sobre força ao desenvolvimento de estratégias de ensino fundamentados num modelo didático construtivista: um estudo multi-caso envolvendo professores e alunos da $7^{\mathrm{a}}$ classe de Cabinda - Angola. 2010. Tese (Doutoramento) -. Universidade de Trás-0S-Montes e Alto Douro, Vila Real, 2010. 
NZAU, Domingos K. Desenvolver uma tarefa especifica com professores para melhorar o ensino em sala de aula. In: LOPES, José B.; VEIGAS, Clara; PINTO, Alexandre (ed.). Melhorar práticas de ensino de ciências e tecnologias. Lisboa: Sílabo, 2018. p. 85-100.

NZAU, Domingos K; LOPES, José, B.; COSTA, Nilza. Formação continuada de professores de física, em Angola com base num modelo didático para o campo conceptual de força. Revista Brasileira de Ensino de Física, São Paulo, v. 34, n. 3, p. 3402-3414, 2012.

OCDE. Organization of Economic Co-operation and Development. PISA 2015 Results: excellence and equity in education. v.1. Paris: ORGANIZATION OF ECONOMIC CO-OPERATION AND DEVELOPMENT, 2016. Disponivel em: https://www.keepeek.com/Digital-Asset-Management/oecd/education/pisa-2015-resultsvolume-i_9789264266490-en\#page1. Acesso em: mar. 2018.

OGBORN, Jon et al. Explaining science in the classroom. Buckingham: Open University Press, 1996.

PEIXE, Paula et al. Os temas DNA e biotecnologia em livros didáticos de biologia: abordagem em ciência, tecnologia e sociedade no processo educativo. Acta Scientiae, Canoas, v. 19, n. 1, p. 177-191, 2017.

RENNIE, Léonie. Reassessing the role of literacy in technology education. In: FISHER, Darrell; MARSH, Tyson (ed.). Proceedings of the third conference on science, mathematics and technology education: East London, South Africa, Key Center for Science and Mathematics, Curtin University of Technology, Perth, Western Australia. v. 1. [S. I.: s. n.], 2003. p. 33-47.

RENNIE, Léonie; STOCKLMAYER, Susan M.; GILBERT, John K. Supporting self-directed learning in science and technology beyond the school years. New York: Routledge, 2019.

ROBERTS, Douglas. Competing visions of scientific literacy. In: LINDER, Cedric et al. (ed.), Exploring the landscape of scientific literacy. New York: Routledge, 2011. p. 11-27.

RODRIGUES, Rui. Sonangol: o petróleo e a estratégia de desenvolvimento económico em Angola. 2013. Dissertação (Mestrado) - Universidade Aberta, Lisboa, 2013.

SANTOS, Maria Eduarda. A cidadania na "voz" dos manuais escolares: 0 que temos? 0 que queremos? Lisboa: Livros Horizonte, 2001.

SCOTT, Philips. Teacher talk and meaning making in science classrooms: a Vygotskian analysis and review. Studies in Science Education, London, v. 32, n. 1, p. 45-80, 1988.

SHUMBA, Overson. Tackling educational quality and epistemological access concerns in science and technology education in Africa: the "learning-as-connection" imperative. African Perspective of Research in Teaching \& Learning, Sovenga, v. 1, n. 1, p. 4-21, 2017.

SILVA, Rosa. Processo de formação inicial de professores de português em Angola. Dissertação (Mestrado) - Universidade do Minho, Braga, 2011. 
SJOBERG, Swein; SCHREINER, Camilla. How do learners in different cultures relate to science and technology? Results and perspectives from the project ROSE (the Relevance of Science Education). AsiaPacific from on Science Learning and Teaching, Hong Kong, v. 6, n. 2, p. 1-17, 2005.

TURNER, Jon. Accounting for explanation in popular science text: a scheme and a case study. Public Understanding of Science, London, v. 13, n. 4, p. 331-346, 2004.

WALKER, Graham et al. Models to build capacity for African science centres and science communication: needs and assets. Journal of Science Communication, Trieste, v. 19, n. 1, A05, 2020.

Recebido em: 14.11.2019.

Revisado em: 04.06.2020.

Aprovado em: 24.11.2020.

Ana Sofia Afonso é professora auxiliar do Instituto de Educação / Centro de Investigação em Educação (IE/CIEd) da Universidade do Minho, Portugal. É PhD Reading, UK, 2005. Desenvolve a sua investigação no âmbito da educação em ciências. É membro do corpo editorial da Revista Portuguesa de Educação.

Daniel A. Freitas é professor de física no Departamento de Ciências Exatas do Instituto Superior de Ciências de Educação do Huambo, Angola. É mestre em ciências da educação, pela Universidade do Minho, Portugal, 2019. Tem interesses de investigação na área da educação em ciências. 